\title{
Caregiver Opinions about Fragile X Population Screening
}

\author{
Donald B. Bailey Jr., Ph.D., \\ RTI International
}

Ellen Bishop, M.S.,

RTI International

Melissa Raspa, Ph.D., and

RTI International

Debra Skinner, Ph.D.

University of North Carolina at Chapel Hill

\section{Abstract}

Purpose-To determine caregiver perceptions about population screening for fragile $\mathrm{X}$ and examine factors potentially associated with support for screening.

Method-We asked 1,099 caregivers of a child with fragile X syndrome or a fragile X carrier to rate whether free, voluntary screening should be offered preconception, prenatally, neonatally, or when problems occur. Caregivers chose a preferred time for screening, reported whether screening would affect parent-child bonding, indicated preferences for carrier detection, and gave reasons for their choices.

Results-Caregivers endorsed all forms of screening, but prenatal screening was less strongly endorsed than preconception or postnatal screening. Most (79\%) preferred preconception carrier testing, allowing more options when making reproductive decisions. Most thought that screening should also disclose carrier status and believed a positive screen would not negatively affect parent-child bonding. Maternal education, caregiver depression, family impact, and severity of disability were not associated with screening opinions, but parents who only had carrier children were less likely to endorse prenatal screening.

Conclusion-Caregivers of children with fragile $X$ widely endorse screening. But because different parents will make different choices, screening may need to be offered at multiple times with careful consideration of consent and informed decision making.

\section{Introduction}

The possibility of population screening for fragile X syndrome (FXS), the most common cause of inherited intellectual disability, demonstrates the complexities inherent in policy decisions. ${ }^{1}$ FXS results from an expansion of the FMR1 gene to more than 200 CGG repeats, resulting in a reduction or elimination of FMRP, a protein necessary for normal brain development. Currently, DNA testing is required to detect FXS (c.f., Tassone et al. ${ }^{2}$ ), which means that any screening that detects $F M R 1$ gene expansions could also identify premutation carriers (55 to 200 CGG repeats). In this paper, we use $F X S$ to refer to individuals who have the syndrome and $F X$ to refer to all $F M R 1$ gene expansions, including premutation carriers. Female carriers can have children with FXS; female carriers are at 
increased risk for ovarian insufficiency and males (and to a lesser extent females) for fragile $\mathrm{X}$ tremor-ataxia syndrome (FXTAS), both adult-onset conditions. ${ }^{3}$

Symptoms of FXS (developmental delay, sensory issues, behavior or attention problems) are not evident at birth, gradually appearing as developmental delays during the first 2 years of life. Because of the lack of symptom specificity and delays in genetic testing, the average age of diagnosis is 35-37 months. ${ }^{4}$ Population screening for FX is possible; could occur at various times with varying benefits and costs; and could include carrier screening, screening for affected individuals, or both. Because FX is inherited from carrier parents, preconception screening could enable reproductive decisions prior to pregnancy. ${ }^{5}$ Prenatal screening could be offered to determine maternal carrier status or whether the fetus has FX. ${ }^{6,7,8}$ Newborn screening could determine whether a neonate has FX. ${ }^{9}$ In the early childhood period, screening could be offered selectively to high-risk populations ${ }^{10}$ or at the first sign of developmental problems. Each option has its own merits and limitations ${ }^{11}$. The opinions of various stakeholders-professionals, the general public, parents—should inform decisions about when and how to offer screening.

Professional organizations constitute one important stakeholder perspective, but no one organization speaks for all forms of screening. The American College of Medical Genetics ${ }^{12}$ and a joint statement by the Child Neurology Society and the American Academy of Neurology ${ }^{13}$ recommend that any child with unexplained delays be tested for FXS. The American Academy of Pediatrics has no formal position on FX testing, but the Committee on Genetics urged pediatricians to consult with clinical geneticists to reduce the time between presenting signs and a genetic diagnosis. ${ }^{14}$ The American College of Obstetricians and Gynecologists ${ }^{15}$ recommends offering prenatal testing to any known FX carriers; FXS testing for any child with developmental delay, autism, or autistic behavior; and carrier testing to women over 40 years of age with ovarian failure or an elevated follicle-stimulating hormone level. The National Society of Genetic Counselors ${ }^{16}$ and a multicenter working group of genetic counselors ${ }^{17}$ suggest testing possibly affected individuals followed by cascade testing of extended family members once a target individual has been confirmed.

Practicing professionals may or may not agree with an organization's policy statement. A 2005 survey of pediatricians found that only about one-third would support newborn or infant population screening for FXS. ${ }^{18}$ However, in a 2009 survey, $78 \%$ of pediatricians believed that newborn screening for FXS would be beneficial for children and families, and $58 \%$ believed that parents should be offered FXS screening for their infant as part of wellchild care. ${ }^{19}$ A 2006 survey of genetic counselors reported that $20 \%$ supported newborn screening, 36\% supported population screening later in infancy, and $73 \%$ supported testing of high-risk infants. ${ }^{20}$ In a 2009 survey of physician geneticists and genetic counselors, about $60 \%$ supported newborn screening for FXS but were less supportive if screening identified carriers. ${ }^{21}$ When asked to choose the best screening model, $72 \%$ endorsed either preconception universal screening (29\%) or high-risk population screening (43\%).

Assessing general public opinion is hampered by the public's general lack of awareness of genetics and screening, and lack of knowledge about conditions such as FXS or the difference between carrier and affected status. ${ }^{22} \mathrm{We}$ are not aware of any surveys assessing population opinions about FX screening. However, one indication can be found in uptake rates when parents are offered screening. A recent review found 10 studies in which FX screening was offered to pregnant or preconception women of reproductive age. ${ }^{23}$

Considerable variability in acceptance rates was reported, ranging from $8 \%$ to $92 \%$. Because the studies were conducted in different countries using different protocols for screening at different times, it is impossible to make a general statement about the acceptability of FX screening to the "general public," although most studies report that once women understand 
the information that could be gained, most support voluntary screening options. Two studies have reported acceptance rates in FX newborn screening. A pilot study offering screening for FXS to mothers of 1,844 male infants born in South Carolina reported a 79\% acceptance rate. ${ }^{24} \mathrm{~A}$ recent study offering screening for FX (premutation and full mutation) to parents of 2,137 male and female newborns in North Carolina reported that $63 \%$ elected to participate. $^{25}$

A final perspective is the opinions of families who have a child with FXS. Patient advocacy groups historically have exerted a strong influence on screening programs, but even families who have experienced a medical condition in one of their children vary in their opinions about screening. ${ }^{26}$ Relatively little is known about the opinions of parents of children with FXS, limited to a single study. ${ }^{27}$ Of 442 mothers and fathers from 290 families, most supported voluntary FX screening at all possible times (preconception, prenatal, newborn, high-risk screening); when forced to choose only one option, most (80\%) chose "before a woman gets pregnant." Most parents felt that screening would not disrupt the bond between parent and child, and most endorsed disclosure of carrier status for both prenatal (87\%) and newborn (94\%) screening. Demographic variables (gender, education, income) were not associated with screening opinions, but religiosity was moderately related to prenatal screening.

The present study replicates and extends the 2003 Skinner et al. study, using a much larger sample of families $(1,099)$ who have at least one child with FX (families could have a child with FXS or only premutation carriers) and examining whether a broader range of variables (respondent education level, age, history of depression, family configuration, and perceived impact of FX on the family) was associated with screening opinions. We hypothesized that families who had experienced more negative ramifications of FX (depression, more than one affected child, more severely affected children, and cumulative negative family impact) would be more likely to support a variety of screening options.

\section{Methods and Materials}

The data reported were collected as part of a U.S. FX survey. ${ }^{28}$ Parents or other caregivers provided information about a range of topics, including age of diagnosis, co-occurring conditions, school services, adult life, and family adaptation. The opinion questions regarding population screening are the focus of this paper.

\section{Subjects}

The sample was a large but non-representative group of parents or other caregivers from each of 1,099 families of children with FX who responded to all screening items in the national survey. Most respondents were mothers (87\%); the remainder were fathers (9\%), grandparents, or others (4\%). Most (92\%) were Caucasian, 4\% Hispanic, 2\% African American, and $2 \%$ from other races or ethnicities. The group was better educated and more affluent than the U.S. population. More than half (58\%) had a college degree or higher, 27\% had some college, and $15 \%$ had a high school degree or less; $56 \%$ reported a household income of greater than $\$ 75,000$ per year. Respondents ranged in age from 16 to 89 years $(\mathrm{M}=47)$.

\section{Procedures and Instrumentation}

Information about the survey was circulated by three FX foundations, researchers, and clinicians. Families completed the survey on the Internet $(76 \%)$ or by calling a toll-free number (24\%). The survey consisted primarily of closed-ended questions about each child 
as well as the family as a whole. A complete description of the survey procedures and major findings are provided in Bailey, Raspa, and Olmsted. ${ }^{28}$

One section addressed parent opinions about FX population screening. We used the same questions from our earlier article ${ }^{27}$ for comparative purposes. On a scale from 1 (strongly disagree) to 5 (strongly agree), caregivers indicated whether they agreed that free and voluntary testing should be offered: (a) to identify if a woman is a carrier of FX before pregnancy (preconception carrier screening), (b) to identify if a woman is a carrier during pregnancy (prenatal maternal screening), (c) to identify if a baby has FX before birth (prenatal fetal screening), (d) to identify if a newborn has FX shortly after birth (newborn screening), and (e) to identify a child with developmental or behavioral problems (problembased screening). Caregivers were then asked, "If you had to choose only one of the following statements, which would it be?" followed by the above five options plus "genetic testing for FX should not be offered at any time," "other (please specify)," and "don't know." Two questions asked how prenatal or newborn screening might affect bonding between caregiver and child (more difficult, no effect, easier, don't know). Finally, parents were asked, "If you or your spouse/partner had a genetic test during pregnancy that showed that your baby was not affected, but is a carrier of FX, would you want to be informed of this at that time?" (yes, no, don't know). A similar question was asked about newborn carrier identification. For several questions (best time for screening, bonding, knowing carrier status), an open-ended section asked parents to explain their choice.

\section{Data Analysis}

SAS (Version 9, Cary, NC) and SUDAAN ${ }^{\circledR}$ (Research Triangle Institute, Research Triangle Park, NC) were used for all quantitative analyses. Percentages were calculated for most variables, including demographic information and item response distribution. Logistic regression models were used to determine whether parent opinions were associated with four caregiver variables and two child variables. Of the 1,099 families, 1,045 were included in the logistic regression models because they had no missing values. Content analysis was conducted for all open-ended responses.

Family predictors-Two caregiver variables (respondent education level, respondent age) were incorporated to test the assumption that respondents with more education or with younger children would be more supportive of screening. Two additional caregiver variables (respondent history of depression, perceived impact of FX on the family) tested the assumption that families more negatively affected by FX would be more supportive of screening. Respondents reported whether they had ever been diagnosed or treated for depression, and if so, how many times. Respondents were assigned to one of three groups: never $(64 \%)$, once $(15 \%)$, or two or more times $(21 \%)$. With regard to family impact, respondents were assigned to one of these groups depending on their response to the question: "Overall, thinking about the impact of FX on your family, has it been mostly positive (18\%), somewhat positive (35\%), somewhat negative (33\%), or mostly negative $(14 \%) ? "$

Child predictor variables-Two explanatory variables combined information on the mutation status and level of severity of children with FX. Our assumption was that more children with FX and the cumulative severity of child impact would be associated with greater endorsement of screening. We created four mutually exclusive groups (family configuration) based on the number and genetic status of the family's children: Group 1: one or more children with the premutation FX and no children with FXS $(\mathrm{N}=67,6 \%)$; Group 2: one or more females with FXS and no males with FXS (N = 111, 11\%); Group 3: only one 
male with FXS, but possibly female children with FXS ( $\mathrm{N}=727,70 \%)$; and Group 4: more than one male with FXS and possibly female children with FXS $(\mathrm{N}=140,13 \%)$.

A severity score was calculated as the sum of total conditions for all affected children. Following the procedures reported by Ouyang, Grosse, Raspa, and Bailey, ${ }^{29}$ the total conditions score for each child ranged from 0 to 9 , reflecting the number of "yes" answers to questions about diagnosis or treatment for developmental delay or eight co-occurring conditions (attention, hyperactivity, aggression, self-injury, autism, seizures, anxiety, depression). This variable reflects the total number of co-occurring conditions in the family. For example, in a family with two affected children with total co-occurring conditions scores of 3 and 6 , respectively, the cumulative severity score would be 9 . Across the sample, the severity score ranged from 0 to 31 , with a median of 5 , and a mean of $5.75(\mathrm{SD}=3.72)$.

A logistic regression model was run for each screening option (preconception carrier, prenatal maternal carrier, prenatal fetus, newborn, or problem-based screening). Each model included respondent education and age, history of depression, perceived family impact, family configuration, and the cumulative severity score. To simplify the analysis, we converted the ordinal scales ranging from 1 (strongly disagree) to 5 (strongly agree) to 0 (undecided/disagree/strongly disagree) or 1 (agree/strongly agree).

\section{Results}

\section{Opinions about Screening}

Caregiver opinions are displayed in Figure 1. Most either agreed or strongly agreed that free, voluntary screening should be offered at all times, but with substantial variability: preconception carrier screening (83\%), prenatal maternal carrier screening (68\%), prenatal fetal screening (61\%), newborn screening (84\%), and problem-based screening (89\%). A comparison of the combined prenatal screening options with the combined preconception or postnatal screening options indicates that parents were significantly less likely to endorse prenatal screening of either mother or fetus than preconception, newborn, or problem-based screening, $\chi^{2}(1, N=1,099)=338.3, p<.0001$. Prenatal screening is the option for which parents were more likely to indicate "uncertain," likely reflecting the controversies and difficult decisions associated with prenatal testing.

\section{Forced Choice Selection}

When forced to select one option, about three-fourths (76\%) preferred preconception carrier screening. Of these, 283 caregivers provided a reason; the vast majority (89\%) said that preconception screening would inform reproductive decisions. Most comments indicated that preconception diagnosis would provide more reproductive control and options ("If this information is known prior to conception, a woman can make an informed decision about having a child." "I feel testing before becoming pregnant offers the greatest number of choices.") Other comments indicate that the most likely benefit would be to avoid the risk of having a child who could have FXS ("I love my child dearly, but I would have liked to have the option to not have a child with this disability.") and, for some, to pursue adoption or assisted reproductive technology ("If I had known, I wouldn't have gotten pregnant with my own genes.").

Approximately 9\% preferred newborn screening. Almost all of the 40 comments stated that newborn screening would make it possible to provide special education or therapies as early as possible ("If you know that the child has fragile X shortly after birth you could get better education for the baby instead of waiting until 2 years old." "The earlier the intervention for that child, the better the outcome for that child's future"). A few parents also noted that newborn screening would have prevented the frustrations they experienced not knowing 
whether the child had a problem or its cause ("Had he been tested I would have known from the get go and had closure-it's the not knowing what is wrong with your newborn that drives you crazy."). For both preconception and newborn screening, some parents saw screening at these times as precluding an abortion that might occur if the diagnosis was during pregnancy.

About 7\% preferred screening once developmental or behavioral problems occur. The 31 comments reflected the predominant theme that diagnosis should only happen when a problem becomes evident ("There is already so much for a mother to learn and do with a newborn. If there are no signs or symptoms at birth, then why throw it at them then when 4-6 months later would be fine.").

Only 3\% endorsed prenatal screening as the best time. Comments indicated that FX screening should be offered concurrently with other prenatal tests for abnormalities like Down syndrome. Only one woman said she would have used this information for pregnancy termination. Other parents wrote that prenatal testing would inform them of the circumstances they would face but did not elaborate. Over a third indicated that information during the prenatal period would help prepare for the future ("So parents can prepare for what lies ahead." "Having a diagnosis before birth allows for therapies to be lined up to begin as needed as soon as possible."). Only $1.4 \%$ felt that screening should not be offered at any time, and $3.7 \%$ either did not know or wrote extraneous comments.

\section{Effects on Bonding}

In general, caregivers did not believe that a positive test for FX would affect bonding. A majority reported that a positive test would have no effect, whether screening during pregnancy $(58 \%)$ or shortly after birth $(63 \%)$. Over 500 comments were submitted by the caregivers who said that screening would have no effect on bonding. Virtually all of them said that they would love and accept their child regardless of genetic status ("When you bring a child into the world you are going to bond or not no matter what 'condition' it may have." "I would have fallen in love with him the minute I first held him no matter what.").

Some families thought that prenatal $(9 \%)$ or newborn (13\%) screening would make bonding easier. Their written comments suggested that screening would explain abnormalities in development, providing more understanding or preventing feelings of guilt or blame ("I blamed myself for his lack of showing affection early on, his learning difficulties." "We were frustrated with not knowing what was different about him. This had a negative effect on bonding with him-if we knew what was up, there would have been less frustration.”).

A minority of families felt that it might make bonding more difficult (11\% prenatal screening, $8 \%$ newborn screening). These families wrote that knowing might have made them grieve or worry, and although they loved their child, they were concerned that these feelings could have had a negative impact. They noted that knowing would have affected the positive experience of pregnancy, and their views of and early interactions with the child ("I would have been so scared. I think I would have cried and worried my whole pregnancy and not enjoyed it like I did." "Most people would expect great things from their offspring; knowing there is a problem right away would decrease my ability to encourage interaction and development.").

But many caregivers acknowledged that they did not really know what the effect of prenatal (22\%) or newborn (15\%) screening might be. Comments reflected ambivalence about wanting to know but not wanting to worry about the negative effects knowing could bring ("I think I would still love and bond with the baby, but the trepidation of the unknown 
would interfere with the joy of the pregnancy." "I want to believe that it would make no difference, and I don't think it would, but in trying to be honest, I don't really know.").

\section{Carrier Testing}

Most parents indicated that they would like to be informed about carrier status, either with prenatal (86\%) or newborn $(92 \%)$ screening. The major reasons given in the 700 comments included the desire to have any and all relevant health information about their child, the feeling that they have a right to know this information, and the potential utility of information in preparing their child for the future ("If it was known, I'd want to know. I wouldn't want someone keeping the information from me, and I would probably tell my child early so they'd grow up knowing it, in an age-appropriate manner."). The parents who did not want to know this information or were uncertain mostly questioned whether the information had any real utility and whether knowing would cause unnecessary worry.

\section{Modeling}

Despite the considerable variability in the predictor variables, only one (family configuration) was associated with screening opinions. Families who only had children with the premutation (and no children with the full mutation) were significantly less likely to endorse fetal prenatal screening than families who had a male child with the full mutation $(\mathrm{OR}=.48, p<.01)$. Interestingly, families who had two or more male children with the full mutation tended to be less supportive of screening than families who only had female children with the full mutation or families with only one male child with FXS, although this difference only reached significance for prenatal maternal carrier screening $(\mathrm{OR}=.61, p<$. 03).

\section{Discussion}

Botkin ${ }^{30}$ recently wrote a commentary entitled: "Newborn Screening for Fragile X Syndrome: Do We Really Care What Parents Think?" Since newborn screening historically has been conducted without parental consent under a public health protocol for conditions needing prompt treatment, parent opinions about screening are rarely sought. But screening for FX is a more complicated issue, since no medical treatment is currently available and carriers would be identified. Furthermore, some individuals with FXS are much more seriously affected than others, and the consequences for some families are more negative than for others. How, when, and whether to offer population screening for FX in the absence of clinical symptoms is a complex set of questions that requires data from multiple perspectives. Parents and other caregivers of affected children comprise an important stakeholder group whose opinions about screening need to be known. In this article we used a sample of more than 1,000 families who had a child with the fragile $\mathrm{X}$ premutation or the full mutation FXS to determine caregiver opinions about various forms of population screening and to determine whether the severity or magnitude of the impact of FX on the family had any bearing on parent opinions.

The majority of caregivers supported screening for both the full mutation FXS as well as for premutation carriers. They endorsed screening at all of the times presented, though ratings of prenatal testing were significantly lower, reflecting the limited options for doing anything at that time and perhaps concerns about abortion. This finding is consistent with other research showing that, for the most part, parents want genetic and health information that has any bearing on the well-being of their children. ${ }^{31-33}$ Studies of families of children with other conditions vary in the extent to which the availability of a known condition-specific treatment affects parent opinions. ${ }^{34-36}$ But consistent with most of these studies, many parents of children with FXS felt that earlier identification would enable access to early 
intervention and therapy services, even though those services are not FXS specific and their efficacy with FXS has not been demonstrated. This finding suggests that parents generally have a broad view of what constitutes treatment and treatability. ${ }^{37,38}$ However, some parents reflected, as shown in other studies, ${ }^{39}$ that they were ambivalent about knowing, because screening might mean they would not have the children they have now.

When forced to choose one time for screening, the majority (76\%) of caregivers endorsed preconception screening. The common theme among virtually all of the respondents was the desire to know ahead of time so that they could "have a choice" about whether to risk having a child with FXS. The strong preference for preconception screening found in this study, however, contrasts with the $20 \%$ acceptance rate in the only pilot study reporting uptake rates for nonpregnant women. ${ }^{5}$ Many factors likely influence acceptance of preconception carrier testing, including maternal age, cost of the test, family history of disability or developmental problems, perception of risk, and intent to have a child in the near future. Voluntary population-based preconception carrier testing, while strongly endorsed by parents of affected children, will likely be challenging to implement in a way that achieves any broad-based public health goals, especially given the fact that nearly $50 \%$ of U.S. pregnancies and more than $40 \%$ of pregnancies worldwide are unintended. ${ }^{40,41}$

We had hypothesized that families more affected by FX (higher rate of caregiver depression, more severely affected children, perceived negative family impact) would more strongly endorse all forms of screening. Surprisingly, none of these variables were associated with opinions about screening, nor was caregiver age or education. The only variable associated with screening opinions was family configuration; families who only had premutation children were significantly less likely to endorse prenatal screening, although the magnitude of difference was relatively small. This finding suggests that families who only have carrier children may feel less urgency about the need to know, even though most still endorsed all forms of screening.

Although this is by far the largest study of parent opinions about FX screening, the survey sample was not representative of families with children with FX in the U.S. population; thus, the findings must be interpreted accordingly. Very few families from ethnic minority groups participated and the sample reported higher levels of income than the U.S. population.

Because family income and maternal education are highly correlated and we had more variability in maternal education, we examined the association between maternal education and opinions about screening but not for minority status because cell sizes were small. The study of necessity is based on caregiver report. Although opinion data are useful, some outcomes (e.g., effects of screening on parent-child bonding) can only be evaluated definitely in the context of a prospective longitudinal study. We also relied on caregivers' reports of other variables such as co-occurring conditions and genetic status of their children. Although parents and other caregivers can provide important information about the nature and consequences of a condition and the symptoms that are of most concern to them, we did not have diagnostic confirmation of these study variables. Finally, these findings may not pertain to opinions of families in countries other than the United States.

Despite these limitations, this study provides a definitive view of caregiver perspectives on population screening for FX in the U.S. Consistent with findings from our earlier study, ${ }^{27}$ parents who have experienced raising a child with FX strongly endorse all forms of population screening, although they are significantly less likely to endorse prenatal screening, and when forced to choose, most would prefer preconception carrier testing.

The empirical base for population screening for FX remains scant. ${ }^{23}$ More systematic investigations comparing screening options and examining the long-term costs and benefits 
of each are needed. These investigations will need to consider the likely variability in individual preferences for screening and the subsequent need for, and costs associated with, informed consent and informed decision making at various times for screening. If current clinical trials of mGluR5 antagonists and GABA agonists addressing the core mechanisms affected by FXS ${ }^{42,43}$ show treatment efficacy and studies demonstrate that treatment is safe and maximally effective when provided early in life, it will be interesting to see whether and how the dynamic of population screening for FX changes.

\section{Acknowledgments}

Preparation of this article was supported in part by the Centers for Disease Control and Prevention (CDC) and the Association for Prevention Teaching and Research (APTR) Cooperative Agreement No. U50/CCU300860, Project TS-1380. The findings and conclusions in this publication are those of the authors and do not necessarily represent the views of CDC or APTR. Partial support was also provided by the Eunice Kennedy Shriver National Institute for Child Health and Human Development (P30 HD003110-S1), and the Ethical, Legal, and Social Implications Research Program/National Human Genome Research Institute (5P50HG004488).

\section{References}

1. Ross LF, Acharaya K. Policy decisions in designing a fragile X population screening program. Genet Med. 2008; 10(10):711-713. [PubMed: 18813132]

2. Tassone F, Pan R, Amiri K, Taylor AK, Hagerman PJ. A rapid polymerase chain reaction-based screening method for identification of all expanded alleles of the fragile X (FMR1) gene in newborn and high-risk populations. J Mol Diag. 2008; 10(1):43-49.

3. Rodriguez-Revenga L, Madrigal I, Pagonabarraga J, et al. Penetrance of FMR1 premutation associated pathologies in fragile X syndrome families. Eur J Human Genet. 2009; 17:1359-1362. [PubMed: 19367323]

4. Bailey DB, Raspa M, Bishop E, Holiday D. No change in the age of diagnosis for fragile X syndrome: findings from a national parent survey. Pediatrics. 2009; 124:527-533. [PubMed: 19581269]

5. Metcalfe S, Jacques A, Archibald A, et al. A model for offering carrier screening for fragile X syndrome to nonpregnant women: results from a pilot study. Genet Med. 2008; 10(7):525-535. [PubMed: 18580686]

6. Cronister A, DiMaio M, Mahoney MJ, Donnenfeld AE, Hallam S. Fragile X carrier screening in the prenatal genetic counseling setting. Genet Med. 2005; 7(4):246-250. [PubMed: 15834242]

7. Musci TJ, Caughey AB. Cost-effectiveness analysis of prenatal population-based fragile X carrier screening. Am J Obstet Gynecol. 2005; 192(6):1905-1912. [PubMed: 15970847]

8. Xunclà M, Badenas C, Dominguez M, et al. Fragile X syndrome prenatal diagnosis: parental attitudes and reproductive responses. Reprod Biomed Online. 2010; 21(4):560-565. [PubMed: 20801083]

9. Bailey, DB. Newborn screening for intellectual disability: past, present, and future. In: Glidden, LM., editor. International Review of Research in Mental Retardation. Vol. 36. Burlington: Academic Press; 2008. p. 1-25.

10. Pastore LM, Karns LB, Pinkerton JV, Silverman LM, Williams CD, Camp TR. Acceptance of fragile X premutation genetic screening in women with ovarian dysfunction. Am J Obstet Gynecol. 2006; 194(3):738-743. [PubMed: 16522406]

11. Bailey DB, Skinner D, Davis A, Whitmarsh I, Powell C. Ethical, legal, and social concerns about expanded newborn screening: fragile $\mathrm{X}$ syndrome as a prototype for emerging issues. Pediatrics. 2008; 121(3):e693-e704. [PubMed: 18310190]

12. Curry CJ, Stevenson RE, Aughton D, et al. Evaluation of mental retardation: recommendations of a Consensus Conference-American College of Medical Genetics. Am J Med Genet. 1997; 72(4): 468-477. [PubMed: 9375733]

13. Shevell M, Ashwal S, Donley D, et al. Practice parameter: evaluation of the child with global developmental delay - report of the Quality Standards Subcommittee of the American Academy of 
Neurology and the Practice Committee of the Child Neurology Society. Neurology. 2003; 60(3): 367-380. [PubMed: 12578916]

14. Moeschler JB, Shevell MD, the Committee on Genetics. Clinical genetic evaluation of the child with mental retardation or developmental delays. Pediatrics. 2006; 117(6):2304-2316. [PubMed: 16740881]

15. American College of Obstetricians and Gynecologists Committee on Genetics. ACOG committee opinion. No. 338: Screening for fragile X syndrome. Obstet Gynecol. 2006; 107(6):1483-1485. [PubMed: 16738187]

16. McConkie-Rosell A, Finucane B, Cronister A, Abrams L, Bennett RL, Pettersen BJ. Genetic counseling for fragile X syndrome: updated recommendations of the National Society of Genetic Counselors. J Genet Counsel. 2005; 14:249-270.

17. McConkie-Rosell A, Abrams L, Finucane B, et al. Recommendations from multi-disciplinary focus groups on cascade testing and genetic counseling for fragile $\mathrm{X}$-associated disorders. J Genet Counsel. 2007; 16(5):593-606.

18. Acharya K, Ackerman PD, Ross LF. Pediatricians' attitudes toward expanding newborn screening. Pediatrics. 2005; 116(4):e476-e484. [PubMed: 16199673]

19. Kemper A, Bailey DB. Pediatricians' knowledge of and attitudes toward fragile $X$ syndrome screening. Acad Pediatr. 2009; 9(2):114-117. [PubMed: 19329102]

20. Hiraki S, Ormond KE, Kim K, Ross LF. Attitudes of genetic counselors towards expanding newborn screening and offering predictive genetic testing to children. Am J Med Genet Part A. 2006; 140A(21):2312-2319. [PubMed: 17036312]

21. Acharya K, Ross LF. Fragile X screening: Attitudes of genetic health professionals. Am J Med Genet Part A. 2009; 149A(4):626-632. [PubMed: 19291766]

22. Davis TC, Humiston SG, Arnold CL, et al. Recommendations for effective newborn screening communication: results of focus groups with parents, providers, and experts. Pediatrics. 2006; 177(5 Pt 2):S326-S340. [PubMed: 16735260]

23. Hill MK, Archibald AD, Cohen J, Metcalfe SA. A systematic review of population screening for fragile X syndrome. Genet Med. 2010; 12(7):396-410. [PubMed: 20548240]

24. Saul RA, Friez M, Eaves K, et al. Fragile X syndrome detection in newborns-pilot study. Genetics in Medicine. 2008; 10(10):714-719. [PubMed: 18813135]

25. Skinner D, Choudhury S, Sideris J, Guarda S, Buansi A, Roche M, Powell C, Bailey DB. Parents' decisions to screen newborns for fragile $\mathrm{X}$ in a pilot research project. Pediatrics. in press.

26. Paul DB. Patient advocacy in newborn screening: continuities and discontinuities. Am J Med Genet Part C (Seminars in Medical Genetics). 2008; 148C(1):8-14.

27. Skinner D, Sparkman KL, Bailey DB. Screening for fragile $X$ syndrome: parent attitudes and perspectives. Genet Med. 2003; 5(5):378-384. [PubMed: 14501833]

28. Bailey DB, Raspa M, Olmsted MG. Using a parent survey to advance knowledge about the nature and consequences of fragile X syndrome. Am J Intellect Dev Disabil. 2010; 115(6):447-460. [PubMed: 20945998]

29. Ouyang L, Grosse SD, Raspa M, Bailey D. Employment impact and financial burden for families of children with fragile X syndrome: findings from the National Fragile X Survey. J Intellect Disabil Res. 2010; 54(10):918-928. [PubMed: 20796162]

30. Botkin JR. Newborn screening for fragile X syndrome: Do we care what parents think? Pediatrics. 2011; 127:e1593-e1594. [PubMed: 21624877]

31. Watkin PM, Beckman A, Baldwin M. The views of parents of hearing impaired children on the need for neonatal hearing screening. Br J Audiol. 1995; 29(5):259-262. [PubMed: 8838547]

32. Hayes IM, Collins V, Sahhar M, Wraith JE, Delatycki MB. Newborn screening for mucopolysaccharidoses: opinions of patients and their families. Clin Genet. 2007; 71(5):446-450. [PubMed: 17489850]

33. Schaller J, Moser H, Begleiter ML, Edwards J. Attitudes of families affected by adrenoleukodystrophy toward prenatal diagnosis, presymptomatic and carrier testing, and newborn screening. Genet Test. 2007; 11(3):296-302. [PubMed: 17949291]

34. Plass AMC, van El CG, Pieters T, Cornel MC. Neonatal screening for treatable and untreatable disorders: prospective parents' opinions. Pediatrics. 2010; 125e(1):e99-e106. [PubMed: 20026497] 
35. Detmar S, Dijkstra N, Nijsingh N, Rijnders M, Verweij M, Hosli E. Parental opinions about the expansion of the neonatal screening programme. Community Genet. 2008; 11(1):11-17. [PubMed: 18196913]

36. Quinlivan JA, Suriadi C. Attitudes of new mothers towards genetics and newborn screening. J Psychosom Obstet Gynaecol. 2006; 27(1):67-72. [PubMed: 16752878]

37. Bailey DB. The blurred distinction between treatable and untreatable conditions in newborn screening. Health Matrix: J Law-Med. 2009; 19(1):141-153.

38. Bailey DB, Skinner D, Warren SF. Newborn screening for developmental disabilities: reframing presumptive benefit. Am J Public Health. 2005; 95(1):1889-1893. [PubMed: 16195526]

39. Raspberry KA, Skinner D. Negotiating desires and options: how mothers who carry the fragile $X$ gene experience reproductive decisions. Soc Sci Med. 2011; 72(6):992-998. [PubMed: 21333433]

40. Finer LB, Henshaw SK. Disparities in rates of unintended pregnancy in the United States, 1994 and 2001. Persp Sex Reprod Health. 2006; 35:90-96.

41. Singh S, Sedgh G, Hussain R. Unintended pregnancy: worldwide levels, trends, and outcomes. Stud Fam Plann. 2010; 41:241-250. [PubMed: 21465725]

42. Dölen G, Carpenter RL, Ocain TD, Bear MF. Mechanism-based approaches to treating fragile X. Pharmacol Ther. 2010; 127(1):78-93. [PubMed: 20303363]

43. Jacquemont S, Curie A, des Portes V, et al. Epigenetic modification of the FMR1 gene in fragile X syndrome is associated with differential response to the mGluR5 antagonist AFQ056. Sci Transl Med. 2011; 3(64):64ra1. 


\section{Voluntary genetic testing should be offered....}

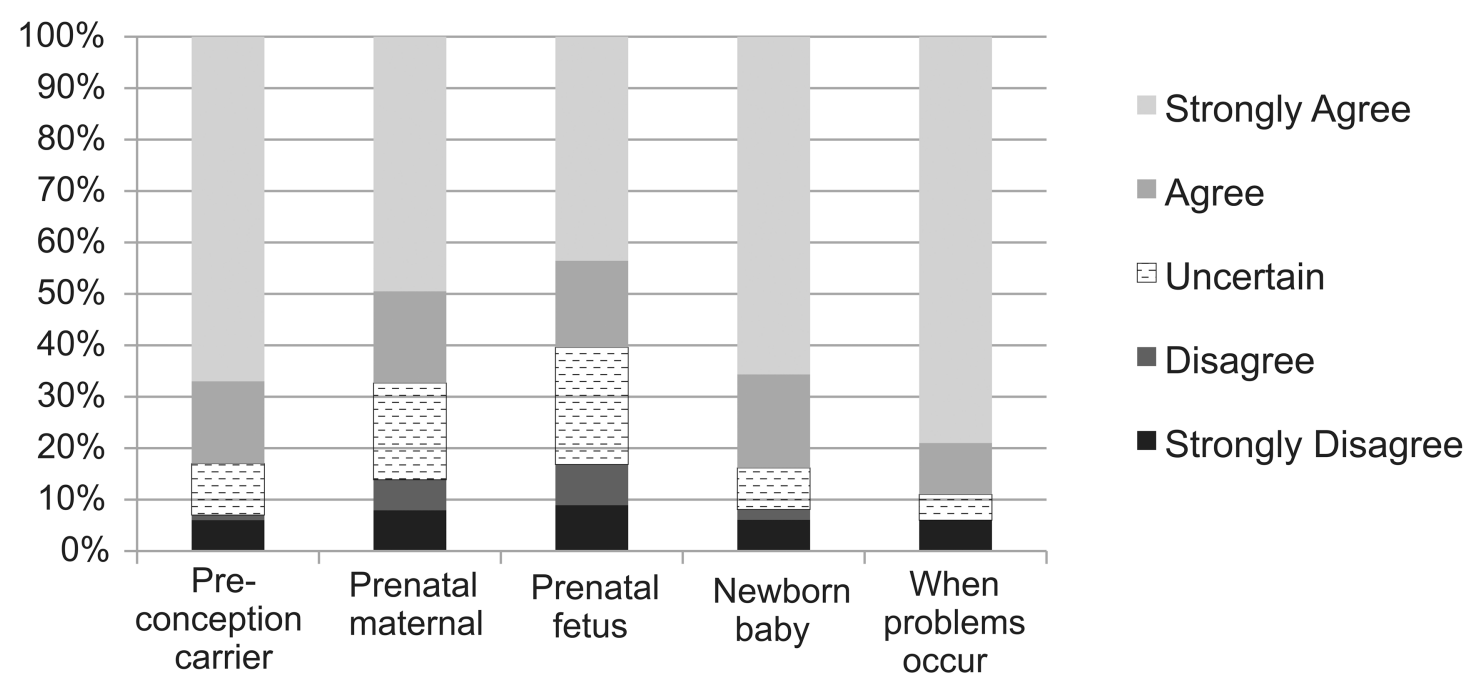

Figure 1.

Percentage of caregivers who agree that free, voluntary genetic testing should be offered at different times. 